Article

\title{
Evaluation of Soybean Plant Introductions for Traits that can Improve Emergence under Varied Soil Moisture Levels
}

\author{
Sruthi Narayanan ${ }^{1, *(1)}$ and Benjamin Fallen ${ }^{2}$ \\ 1 Department of Plant and Environmental Sciences, Clemson University, Clemson, SC 29634, USA \\ 2 Pee Dee Research and Education Center, Clemson University, Florence, SC 29506, USA; bfallen@clemson.edu \\ * Correspondence: skutty@clemson.edu
}

Received: 2 February 2019; Accepted: 26 February 2019; Published: 2 March 2019

check for updates

\begin{abstract}
When drought occurs during the soybean (Glycine max L. Merr.) sowing period, emergence will most likely be affected. We evaluated a diverse panel of 373 plant introductions under controlled environmental conditions for primary root length (PRL) (at 100, 80, 60, 40, and 20\% pot water holding capacity (PWHC); pots filled with potting soil that contained Sphagnum peat moss $(>50 \%)$, bark, and perlite), and time taken for radicle emergence (TRE). The PRL decreased $\geq 75 \%$ at $40 \%$ PWHC, compared to 100, 80, and 60\% PWHC. No genotypes germinated at 20\% PWHC. We identified superior genotypes in terms of PRL and TRE, and found a positive relationship between PRL and emergence that became stronger with decreases in soil moisture levels. This indicates the importance of PRL in improving emergence, which becomes greater with decreases in soil moisture levels or increases in severity of drought. Seed weight was not related to PRL and emergence, indicating that larger seeds will not necessarily have longer PRL and better emergence. As the soybean panel used in this study was previously assessed for traits associated with drought tolerance at the late-vegetative and flowering stages, and the present study assessed it for putative traits related with emergence under various soil moisture conditions, the panel will become an important resource for soybean improvement.
\end{abstract}

Keywords: soybean; primary root length; emergence; moisture stress; radicle emergence; seed weight; variety development

\section{Introduction}

Soybean (Glycine max L. Merr.) is the most important oilseed and one of the most important and affordable protein sources worldwide [1]. Soybean is used as a whole seed for direct human food or is crushed for oil and meal. Soybean oil is the second most widely used vegetable oil in the world, and soybean meal accounts for $70 \%$ of global protein meal consumption [1]. Currently, the United States is the largest soybean producer in the world. Soybean is one of the most planted field crops in the United States, and the second most important crop that contributes to the total crop revenue in the country [1]. However, soybean production in the United States is threatened by several environmental stresses.

Drought is the major environmental factor limiting soybean yield in the United States [2-4]. It has been found that drought was associated with $\sim 13 \%$ of soybean yield variability in the United States over a 50 year period between 1958 and 2007 [5]. Improving yield under drought stress has become a major goal of soybean breeding programs in the United States. Even though drought tolerance is one of the most intractable breeding traits in soybean, researchers were able to identify the first drought-tolerant soybean in the 1980s, for which the drought tolerance behavior was attributed to the plant's ability to exhibit slow wilting under drought stress [4]. Since then, several exotic soybean 
genotypes with the slow wilting trait have been identified [6-8]. Sustained nitrogen fixation has also been linked to drought tolerance in soybean $[9,10]$. In 2016, the first drought-tolerant high yielding soybean cultivar was released by Carter et al. [11]. Currently, new genotypes are in the pipeline for release as drought-tolerant varieties. However, in all these genotypes, drought tolerance has only been evaluated in the late vegetative or reproductive stages.

The soybean crop is most susceptible to drought at two stages: at emergence and from flowering through pod-fill $[12,13]$. To date, most of the drought research has been conducted at the latter stage. Drought often occurs during the planting period of soybean in the southeastern United States and many other soybean-growing regions around the world. In order for soybean to begin germination, the seed must imbibe water at least $50 \%$ of its weight, and more is needed for emergence [14]. It is common in the southeast for farmers to plant soybean seeds in the dry soil, hoping that a following rainfall would ensure emergence, but a prolonged dry spell results in poor germination and emergence, leading to replanting, which can cause a significant financial burden. Soybean varieties with better emergence under low soil moisture levels will have the potential to have a better stand establishment, and thus, drought tolerance at the emergence stage. Currently, no soybean variety in the country is reported to have drought tolerance at the emergence stage.

The sensitivity of imbibed soybean seeds to dehydration varies during the germination period [13]. The transition of a soybean seed from a dehydration-tolerant to susceptible phase temporally coincides with radicle elongation. The dehydration injury is most commonly manifested as lack of emergence as the germinating seeds die before emergence. The soybean root system at emergence is predominantly composed of the primary root that originates as the radicle from a germinating seed [15]. Long primary roots may improve exploration of the soil profile in search of water, and thus, emergence under drought conditions. Thus, genotypes that quickly produce a radicle and possess a long primary root at the emergence stage may have the potential for better emergence and stand establishment under low soil moisture conditions.

In recent years, soybean breeders in the United States have tested numerous plant introductions (PI) from all over the world for putative traits contributing to drought tolerance [7]. Certain promising genotypes such as PI 416937 (slow wilting, collected from Japan) and PI 471938 (slow wilting, collected from Nepal) $[6,16,17]$ have tremendously advanced the soybean breeding programs in the United States for drought tolerance. Exploring genetic variability for putative traits associated with better emergence at low soil moisture levels in a diverse panel of exotic germplasm may identify contrasting genotypes that can be included in crop improvement programs and help develop varieties with drought tolerance at the emergence stage, and the current study was designed for that purpose.

The soybean panel used in this study included diverse genotypes from 10 different countries that were characterized for canopy wilting, water use efficiency, and sustained nitrogen fixation under drought, traits that can be associated with drought tolerance of soybean [9,16-22]. As very little work has been done on soybean emergence in response to drought, we chose this diverse panel to study putative traits associated with emergence under adequate and low moisture levels. In addition, increasing genetic diversity in the breeding populations by including exotic genotypes has been proven to be a promising approach for the soybean breeding programs in the United States for drought tolerance $[7,16,23]$.

The specific objectives of this research were to (1) evaluate a diverse panel of 373 soybean PI's for primary root length (PRL) (under five different moisture levels: 100, 80, 60, 40, and 20\% pot water holding capacity (PWHC)) and time taken for radicle emergence (TRE), (2) identify genotypes with increased PRL and that quickly produce a radicle, and (3) determine whether there is any relationship among emergence, PRL, and seed weight. 


\section{Materials and Methods}

\subsection{Germplasm}

The germplasm collection used in this study consisted of 373 soybean PI's (Table S1). All genotypes were of cultivated soybean (Glycine Max) type, and belonged to maturity group IV. A majority of these genotypes originated from South Korea $(n=246) .60$ genotypes originated from China, 42 from Japan, and 13 from North Korea. Others originated from Georgia $(n=6)$, Russia $(n=2)$, India $(n=1)$, Mexico $(n=1)$, Romania $(n=1)$, and Taiwan $(n=1)$. The panel consisted of two groups of genotypes; the first group included 182 genotypes with high yields $(>2.5 \mathrm{Mg}$ ha -1$)$ and the second group included 191 genotypes with relatively lower yields (<2.5 Mg ha-1) [18,19]. All genotypes possessed good agronomic characteristics in terms of height, lodging, and shattering. The variability in country and province of origin of genotypes maximizes diversity of the panel. The panel was previously genotyped using genome-wide association analysis to identify single nucleotide polymorphism (SNP) markers associated with canopy wilting [20], carbon isotope ratio (a surrogate measure of water use efficiency) [18], and traits associated with nitrogen fixation [19]. More information regarding the genotypes is available from GRIN (Germplasm Resources Information Network, www.ars-grin.gov).

\subsection{Seed Source}

The seeds were originally obtained from GRIN, and were sown under field conditions in the 2016 summer season to increase the seed numbers. The resulting plants were harvested in the fall of 2016. After harvest, the soybean seeds were stored in a cold room at $5.6{ }^{\circ} \mathrm{C}$ and $50 \%$ relative humidity and maintained around $12 \%$ moisture content until use. Two hundred seeds of each genotype were weighed to characterize seed weight (200 seed weight). The seed quality of all genotypes was determined using the protocol given in the 'Uniform Soybean Tests- Southern States' [24]. Visual ratings were used to assess seed quality according to the amount and degree of wrinkled, cracked, greenish, or moldy seeds, using a scale of $1=$ very good, $2=$ good, $3=$ fair, $4=$ poor and $5=$ very poor. Seed quality has been shown to be correlated with seed germination, if conditions for germination are favorable [25]. In addition, we observed $91 \%$ emergence at $80 \%$ PWHC in the present study (see 'Results'), which also indicates good germinability among various genotypes in the original seed lot. The germination rate of the seed lot was tested using random samples of 42 genotypes. Not all genotypes were tested because of limited seed numbers. However, all genotypes were grown, harvested, and stored in a similar manner, and all genotypes were inspected for seed quality. To test germination rates, 100 seeds were placed on moistened germination paper (Seedburo Equipment Co., Chicago, IL, USA) (50 seeds per genotype; thus, two genotypes per germination paper) and placed in a SD8900 germinator (Seedburo Equipment Co., Chicago, IL) at $22{ }^{\circ} \mathrm{C}$ with $12 \mathrm{~h}$ of light and $12 \mathrm{~h}$ of dark for $4 \mathrm{~d}$ [26]. The germination rate of genotypes varied between 90 and $96 \%$.

\subsection{Greenhouse Experiment to Measure Primary Root Length and Emergence}

This research was conducted under controlled environmental conditions at the Department of Plant and Environmental Sciences, Clemson University, Clemson, SC during 2016-2017. A pot-study was conducted in a greenhouse to determine the PRL and emergence of soybean genotypes under various moisture levels (100, 80, 60, 40, and 20\% PWHC). Pots of $1.4 \mathrm{~L}$ volume were filled with saturated potting soil (Sphagnum peat moss $(>50 \%)$, bark, and perlite; Fafard ${ }^{\circledR} 3 \mathrm{~B}$ Mix Metro-Mix ${ }^{8} 830$, SUNGRO Horticulture, Agawam, MA), left to drain overnight, and weighed to obtain weight at $100 \%$ water holding capacity. To get pots at $80,60,40$, and $20 \%$ water holding capacity, pots were left to drop to a weight below that of the intended water holding capacity and rehydrated to the required weight. Three seeds of a single genotype, treated with the fungicide Bean Guard ${ }^{\circledR} /$ Allegiance ${ }^{\circledR}$ [captan (N-[(trichloromethyl)thio]-4-cyclohexene-1,2-dicarboximide)- carboxin (5,6-dihydro-2-methyl-N-phenyl-1,4 oxathiin-3-carboxamide)- metalaxyl ( $\mathrm{N}$-(2,6-dimethylphenyl)$\mathrm{N}$-(methoxyacetyl)alanine methyl ester) at the rate of $2 \mathrm{~g}$ per $\mathrm{kg}$ of soybean seed] were sown at $2.5 \mathrm{~cm}$ 
depth in each pot. Care was taken to sow only whole soybean seeds, not splits or broken seeds. Each genotype was sown in four pots (replications) per each moisture level. At sowing, white-colored polyethylene vinyl acetate (PEVA) shower curtain liners were placed over the pots in order to minimize evaporative loss of water. Seven days after sowing, the emerged seedlings in each pot were counted to estimate emergence \%. An emerged seedling was counted when at least both cotyledons were above the soil surface [27]. After recording emergence, seedlings were carefully pulled from the potting soil without damage to the primary roots. Primary root length was measured by stretching the primary root and measuring the distance between the cotyledonary node and the tip of the primary root. Pots were weighed daily during the whole experiment and watered according to pot weight to maintain them at the required moisture level. The daytime maximum/night time minimum temperatures of $30 / 20^{\circ} \mathrm{C}$ and a photoperiod of $13 \mathrm{~h}$ were maintained in the greenhouse during the whole experiment.

Experimental Design and Statistical Analyses

This experiment was conducted using a split plot design and was repeated or replicated four times, with replications being the blocks. The whole plot factor was moisture level (five levels) separated on benches in the greenhouse, and the sub-plot factor was genotype ( 373 levels). The treatments (moisture levels and genotypes) were arranged in a two-factor factorial design. There were four replications for each moisture level (whole plot factor) and genotype in each moisture level (sub-plot factor). Moisture levels were randomly assigned to greenhouse benches for each replication in time. Also, genotypes were randomly assigned to pots within each moisture level. Genotype and moisture level were considered as fixed effects and replication was considered as a random effect in the analysis. Analysis of variance was performed using the GLIMMIX procedure in SAS (Version 9.4, SAS Institute) to find the effect of moisture levels, genotypes, and their interactions on PRL. Separation of least squares means was done based on the LSD test using the LSMEANS option in the GLIMMIX procedure. Analysis of covariance was performed using the GLIMMIX procedure to find the relationships among emergence, PRL, and seed size of the soybean genotypes [28]. The probability threshold level $(\alpha)$ was 0.05 .

\subsection{Laboratory Experiment to Measure Time Taken for Radicle Emergence}

To estimate the TRE, a laboratory experiment was conducted following the "Rules for Testing Seeds" of the Association of Official Seed Analysts (AOSA) [29]. Twenty seeds of each genotype treated with the fungicide Bean Guard ${ }^{\circledR} /$ Allegiance ${ }^{\circledR}$ [captan (N-[(trichloromethyl)thio]-4cyclohexene-1,2-dicarboximide)- carboxin (5,6-dihydro-2-methyl-N-phenyl-1,4 oxathiin-3-carboxamide)metalaxyl (N-(2,6-dimethylphenyl)-N-(methoxyacetyl)alanine methyl ester) at the rate of $2 \mathrm{~g}$ per $\mathrm{kg}$ of soybean seed] were placed in between moist Whatman no. 42 filter papers in a petri dish (internal diameter, $9 \mathrm{~cm}$ ). Filter papers were thoroughly moistened, but not to the point of dripping, using reverse osmosis (RO) filtered water. Seeds were as uniformly spaced as possible. Only whole soybean seeds, not splits or broken seeds, were used for the experiment. There were four petri dishes (replications) per genotype; thus, a total of 80 seeds were sampled per genotype. Petri dishes with seeds were placed at $25^{\circ} \mathrm{C}$ in an incubator under dark conditions. Each petri dish was checked for radicle emergence every $24 \mathrm{~h}$ up to $384 \mathrm{~h}$, or until $85 \%$ of seeds in that petri dish (i.e., 17 out of 20 seeds) produced a radicle (whichever happens first). A seed was counted to have a radicle when the emerged radicle was of at least $1 \mathrm{~cm}$ in length. In every $24 \mathrm{~h}$, each seed that produced a radicle was counted and removed from each petri dish, and the dishes were returned to the incubator. The hours required by $85 \%$ of the seeds in a petri dish to produce a radicle was denoted as TRE of that particular dish (replication). Filter papers in each petri dish were checked every $24 \mathrm{~h}$ and water was applied to compensate any moisture loss.

\section{Experimental Design and Statistical Analyses}

This experiment was conducted using a completely randomized design with four replications per genotype. Genotype was treated as a fixed effect and replication was treated as a random effect. 
Analysis of variance was performed using the GLIMMIX procedure in SAS to find the effect of genotypes on TRE. The probability threshold level $(\alpha)$ was 0.05 .

\section{Results}

\subsection{Genetic Variability for Primary Root Length and Time Taken for Radicle Emergence}

The analysis of variance results on effects of moisture level, genotype, and/or moisture level-by-genotype interaction on PRL and TRE are given in Table 1. Since no genotypes emerged at $20 \%$ pot water holding capacity, that moisture level was excluded from the analysis of variance for PRL. The effect of genotype was significant on PRL and TRE. The effect of moisture level was significant and the effect of moisture level-by-genotype interaction was not significant on PRL.

Table 1. Analysis of variance results on the effects of moisture level, genotype, and moisture level-by-genotype interaction on primary root length, and the effects of genotype on time taken for radicle emergence.

\begin{tabular}{cccc}
\hline \multirow{2}{*}{ Trait } & \multicolumn{2}{c}{ P Value } \\
\cline { 2 - 4 } & Moisture Level ${ }^{\mathbf{1}}$ & Genotype & $\begin{array}{c}\text { Moisture } \\
\text { Level }^{*} \text { Genotype }\end{array}$ \\
\hline Primary root length $(\mathrm{cm})$ & $<0.0001$ & 0.0164 & 1.000 \\
Time taken for radicle emergence $(\mathrm{h})$ & $\mathrm{N} / \mathrm{A}$ & $<0.0001$ & $\mathrm{~N} / \mathrm{A}$ \\
\hline
\end{tabular}

${ }^{1}$ Primary root length of 373 soybean genotypes were tested at five moisture levels $(100,80,60,40$, and $20 \%$ pot water holding capacity). Since no genotypes emerged at $20 \%$ pot water holding capacity, that moisture level was excluded from the analysis of variance. The time taken for radicle emergence by each genotype was measured at a single moisture level (using adequately moistened filter papers in petri dishes according to the "Rules for Testing Seeds" of the Association of Official Seed Analysts (AOSA) [29]).

Primary root length was similar at 80 and $60 \%$ PWHC (Figure 1). Primary root length at $100 \%$ PWHC was 20\% less than that at 80 and $60 \%$ PWHC. Primary root length drastically decreased at $40 \%$ PWHC, compared to the other moisture levels (75\% decrease, compared to 100\% PWHC and 80\% decrease, compared to both 80 and 60\% PWHC).

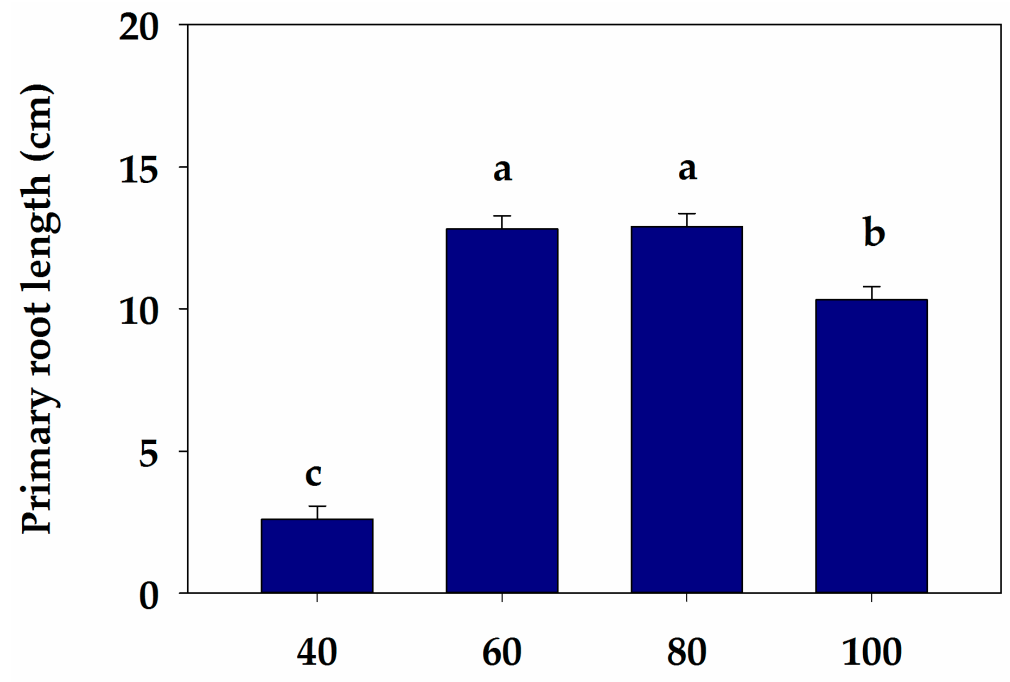

Pot water holding capacity $(\%)$

Figure 1. Primary root length of soybean genotypes at various moisture levels (100, 80, 60, and 40\% pot water holding capacity). Bars represent least squares means and error bars represent standard errors. Least squares means with different letters are significantly different according to the LSD test at $p<0.05$. 
Frequency distributions of PRL (Figure 2) and TRE (Figure 3) showed the extent of genetic variability for these traits. Primary root length ranged between $4 \mathrm{~cm}$ and $14 \mathrm{~cm}$ (Table S1). Time taken for radicle emergence ranged between $48 \mathrm{~h}$ and $336 \mathrm{~h}$ for 369 genotypes; three genotypes failed to produce a radicle even at $384 \mathrm{~h}$ (the total experiment duration) (Table S1). One genotype (PI 532466A) was not tested for TRE due to unavailability of seeds.

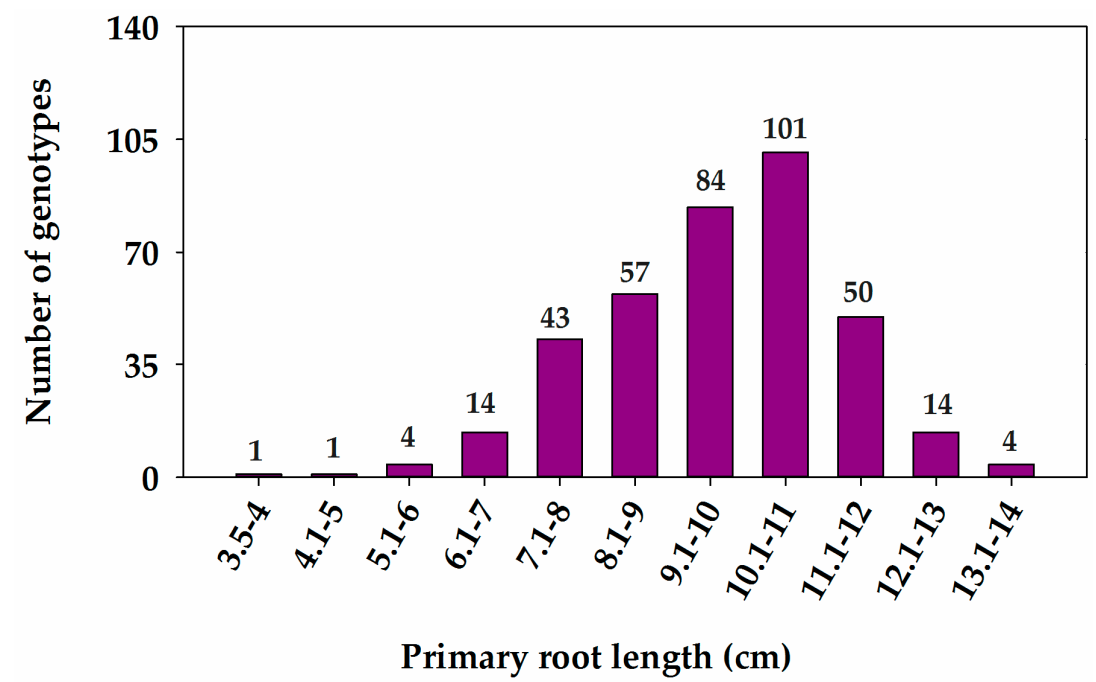

Figure 2. Variation of primary root length [averaged across moisture levels (100, 80, 60, and 40\% pot water holding capacity)] among soybean genotypes. The numbers above the bars indicate the absolute numbers of genotypes in each root length class.

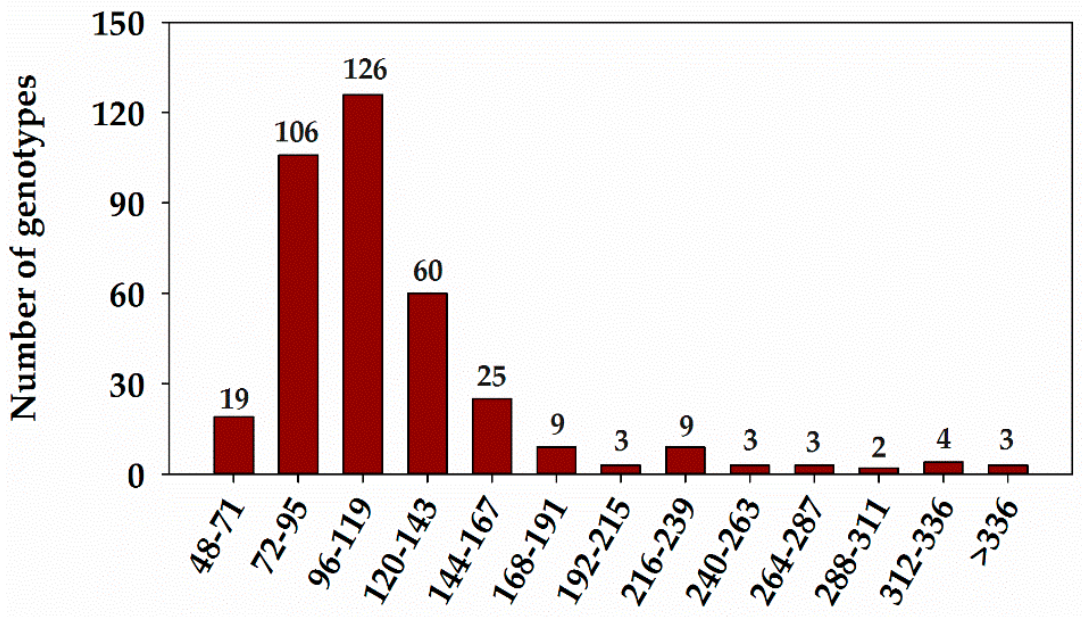

Time taken for radicle emergence $(h)$

Figure 3. Variation of time taken for radicle emergence among soybean genotypes. One genotype (PI 532466A) was not tested for time taken for radicle emergence due to unavailability of seeds. The numbers above the bars indicate the absolute numbers of genotypes in each class.

We identified soybean genotypes with increased PRL across moisture levels, which quickly produced a radicle (Table S1). When averaged across 100, 80, 60, and 40\% PWHC, 18 genotypes had PRL $\geq 12 \mathrm{~cm}$. These genotypes were PI 398939, PI 398965, PI 398987, PI 404199, PI 407892A, PI 408175, PI 424346, PI 424535A, PI 424614, PI 438307, PI 507382, PI 508293, PI 538376, PI 567201D, PI 567606, PI 597480A, PI 603457A, and PI 603543B. Among them, four genotypes (PI 424614, PI 508293, PI 438307, and PI 567201D) had PRL $>13 \mathrm{~cm}$. Genotypes PI 398965, PI 404191, and PI 438307 also had $\geq 80 \%$ emergence, when averaged across all moisture levels. While most genotypes took $\geq 4 \mathrm{~d}$ for radicle 
emergence, 19 genotypes produced a radicle in less than $3 \mathrm{~d}$. These genotypes were PI 407845A, PI 407959A, PI 408124A, PI 424479, PI 508293, PI 538378, PI 538389, PI 561303, PI 567496, PI 567498, PI 567523, PI 567527, PI 567531, PI 567532, PI 567535A, PI 567540A, PI 567572B, PI 567620B, and PI 603543B. Among them, two genotypes (PI 407845A and PI 538389) had $\geq 80 \%$ emergence, when averaged across all moisture levels. All the 11 genotypes that had $\geq 80 \%$ emergence produced a radicle in $\leq 4.5 \mathrm{~d}$ (Table S1).

\subsection{Relationships among Emergence, Primary Root Length, and Seed Weight of Soybean Genotypes}

Analysis of covariance provided the relationships among emergence, PRL, and seed size of soybean genotypes (Table 2). In the analysis of covariance, a significant slope $(p<0.05)$ for the relation between the response variable and co-variate indicates the existence of a relationship between them. When averaged across various moisture levels (100, 80, 60, and 40\% PWHC), emergence (response variable) and PRL (co-variate) were positively correlated with a significant positive slope and an $\mathrm{R}^{2}$ of 0.81 (Table 2). This might be an indication that the co-variate, PRL, positively influences the emergence of soybean. When this relationship was investigated at 100, 80, 60, and 40\% PWHC separately, we found that the relationship was stronger at 60 and $40 \%$ PWHC than at 100 and $80 \%$ PWHC (indicated by larger $\mathrm{R}^{2}$ values at 60 and $40 \%$ PWHC) (Table 2). Two hundred seed weights of the genotypes ranged from 14 to $77 \mathrm{~g}$ (Table S1). Seed weight was not related with emergence and PRL (slopes not significant; Table 2).

Table 2. Analysis of covariance results showing the relationships among emergence, primary root length, and seed weight of soybean genotypes.

\begin{tabular}{|c|c|c|c|}
\hline Variables & Slope ( $p$-Value ${ }^{1}$ ) & Intercept ( $p$-Value) & $\mathbf{R}^{22}$ \\
\hline$y$ - emergence ${ }^{3}$, covariate - primary root length ${ }^{3}$ & $2.222(p<0.0001)$ & $41.47(p<0.0001)$ & 0.81 \\
\hline$y$ - emergence ${ }^{4}$, covariate - primary root length ${ }^{4}$ & $2.833(p<0.0001)$ & $49.28(p<0.0001)$ & 0.54 \\
\hline$y=$ emergence $^{5}$, covariate - primary root length ${ }^{5}$ & $0.162(p=0.17)$ & $88.83(p<0.0001)$ & $\mathrm{N} / \mathrm{A}$ \\
\hline$y=$ emergence $^{6}$, covariate - primary root length ${ }^{6}$ & $2.49(p<0.0001)$ & $37.50(P<0.0001)$ & 0.70 \\
\hline$y=$ emergence $^{7}$, covariate - primary root length ${ }^{7}$ & $4.150(p<0.0001)$ & $2.366(p<0.0001)$ & 0.81 \\
\hline$y=$ emergence $^{3}$, covariate - seed weight & $0.007(p=0.51)$ & $9.173(p<0.0001)$ & $\mathrm{N} / \mathrm{A}$ \\
\hline$y=$ primary root length ${ }^{3}$, covariate - seed weight & $-0.131(p=0.15)$ & $52.16(p<0.0001)$ & $\mathrm{N} / \mathrm{A}$ \\
\hline
\end{tabular}

${ }^{1}$ A significant slope $(P<0.05)$ indicates the existence of a relationship between the 'covariate' and ' $y$ ' variable; ${ }^{2}$ An $\mathrm{R}^{2}$ value is provided for only those relationships for which the slope is significant; ${ }^{3}$ Averaged across $100,80,60$, and $40 \%$ pot water holding capacity (PWHC); ${ }^{4}$ At $100 \%$ PWHC $;{ }^{5}$ At $80 \%$ PWHC; ${ }^{6}$ At $60 \%$ PWHC; ${ }^{7}$ At $40 \%$ PWHC

\section{Discussion}

The soybean panel used in this study was previously utilized for multiple genetic analyses due to its promising diversity and usefulness in soybean breeding [18-20]. The population structure of the panel has been assessed by genome-wide association analysis that revealed novel SNP biomarkers for traits associated with drought tolerance: canopy wilting, carbon isotope ratio (a surrogate measure of water use efficiency), and nitrogen traits [18-20]. These traits were measured at the late vegetative or flowering stages. As the present research provides additional information on the panel related to drought tolerance of the genotypes during the planting period, it increases the usefulness of the panel in soybean breeding for drought tolerance.

We identified the best genotypes in terms of PRL and TRE, (listed in the 'Results' section). Among them, certain genotypes also had high level of emergence. For example, genotypes PI 438307, PI 398965, and PI $404191 \mathrm{had}>12 \mathrm{~cm}$ PRL and $\geq 80 \%$ emergence (when averaged across moisture levels). Similarly, genotypes PI 407845A and PI 538389 produced a radicle in less than $3 \mathrm{~d}$, and also had $\geq 80 \%$ emergence. It is worth noting that genotypes PI 404199, PI 597480A, and PI 603543B, which had a PRL $>12 \mathrm{~cm}$ and PI 567532 and PI 603543B, which produced a radicle in less than $3 \mathrm{~d}$ (Table S1), were slow wilting genotypes [20]. All genotypes with $>90 \%$ emergence at 100, 80, and $60 \%$ PWHC are listed in Table S2. Among them, genotypes PI 398965, PI 404191, and PI 538389 also had $\geq 50 \%$ emergence at $40 \%$ PWHC (Table S3). Interestingly, genotype PI 398965 had $100 \%$ emergence at 100, 80, and 60\% PWHC. The 
superior genotypes listed above may offer useful genetic material for improving the drought tolerance of soybean.

The positive relationship between PRL and emergence of soybean genotypes was stronger at lower moisture levels (60 and 40\% PWHC) (Table 2). The $\mathrm{R}^{2}$ for the relationship between PRL and emergence increased with a decrease in PWHC, suggesting a stronger effect of PRL on emergence at low moisture levels. As primary roots are the first-formed roots in soybean, long primary roots help reach deeper soil layers where water is available and can improve emergence at low soil moisture levels, and thus, drought tolerance at the seedling stage [30,31]. Our results indicate that the importance of PRL in improving emergence becomes greater with decreases in soil moisture levels or increases in drought severity.

Primary root length at 80 and $60 \%$ PWHC was greater than that at $100 \%$ PWHC. This could be because the slight decrease in water availability at 80 and $60 \%$ PWHC, compared to $100 \%$ PWHC, might have triggered primary root growth to improve exploration of water. Primary root length did not decrease at $60 \%$ PWHC, compared to $80 \%$ PWHC. However, PRL drastically decreased at $40 \%$ PWHC, compared to 100, 80, and $60 \%$ PWHC ( $\geq 75 \%$ decrease). This means that low moisture levels such as $40 \%$ PWHC impose a significant stress to soybean primary root growth. Taken together, the above results show that, though up to $40 \%$ decrease in moisture levels from a $100 \%$ PWHC increases PRL, further decreases to low soil moisture contents of $\leq 40 \%$ PWHC will considerably decrease it.

Eleven out of eighteen genotypes that had $>12 \mathrm{~cm}$ PRL (Figure 2) were PI's from South Korea (Table S1). However, in the present study, the numbers of genotypes originating from various countries were not uniform. Also, $66 \%$ of the genotypes originated from South Korea only. Thus, further studies are required to evaluate whether the country of origin has any influence on PRL.

Farmers often expect greater germination and emergence for varieties with larger seeds. In our study, we found that seed weight (related with seed size) had no relationship with emergence and PRL (Table 2). Our results do not support the perception that larger seeds will lead to better emergence and stand establishment. Similar results have been found in our previous research that soybean seed weight is not related with root traits such as total root length, surface area, and volume [32].

Since drought stress, occurring at the planting period of soybean, is common in the southeastern United States and many other soybean growing regions of the world, good emergence at low soil moisture conditions will be a beneficial trait for the varieties developed for these regions. Our research has identified traits that may contribute to this behavior. The genotypes with increased PRL, TRE, and/or emergence can be included in the soybean breeding programs for developing drought tolerant varieties for the southeastern United States and beyond.

In summary, the present study identified genotypes with increased PRL across moisture levels that quickly produce a radicle, which are listed under the 'Results' section. Among them, certain genotypes also had high level of emergence. For example, genotypes PI 438307, PI 398965, and PI 404191 had increased PRL and high level of emergence across moisture levels. Similarly, genotypes PI 407845A and PI 538389, which possessed the ability to quickly produce a radicle, also had high levels of emergence. The PRL had a positive relationship with emergence, suggesting that long primary roots can improve emergence. The relationship was stronger at lower moisture levels, indicating that the importance of PRL in improving emergence becomes greater with decreases in soil moisture levels or increases in drought severity. Seed weight was not related to PRL and emergence, which indicated that larger seeds will not necessarily have greater PRL and better emergence under low and adequate soil moisture levels.

\section{Conclusions}

The present study evaluated a diverse soybean panel of 373 PI's for PRL under five different moisture levels (100, 80, 60, 40, and 20\% PWHC) and TRE, identified genotypes with increased PRL and that quickly produced a radicle, and found a positive relationship between PRL and emergence that became stronger with decreases in soil moisture levels. Because very little or no work has been done on 
soybean emergence in response to drought, and to the best of our knowledge, this study is the first one evaluating a large, diverse soybean germplasm collection for putative traits related with emergence under various moisture levels, our results offer important information and useful genetic material for improving soybean drought tolerance at the emergence stage. As the soybean panel used in this study was previously assessed through genome-wide association analysis for traits associated with drought tolerance at the late vegetative and flowering stages, and the present research provides additional information on the panel, related to drought tolerance of the genotypes during the planting period, it increases the usefulness of the panel in soybean breeding for drought tolerance. Field research for further investigating the relevance of our controlled environmental research is warranted.

Supplementary Materials: The following are available online at http:/ /www.mdpi.com/2073-4395/9/3/118/s1, Table S1: Country of origin, maturity group, 200 seed weight, time taken to produce a radicle, emergence, and primary root length of all 373 soybean genotypes used in the study, Table S2: Soybean genotypes that had $>90 \%$ emergence at 100, 80, and $60 \%$ pot water holding capacity (PWHC), Table S3: Soybean genotypes that had $\geq 50 \%$ emergence at $40 \%$ pot water holding capacity (PWHC).

Author Contributions: Conceptualization, S.N. and B.F.; methodology, S.N.; formal analysis, S.N.; investigation, S.N.; resources, S.N. and B.F.; data curation, S.N.; writing-original draft preparation, S.N.; writing-review and editing, S.N. and B.F.; project administration, S.N.; funding acquisition, S.N. and B.F.

Funding: This research was funded by the South Carolina Soybean Board, grant number 2011346. This material is based upon work supported by NIFA/USDA, under project number SC-1700533.

Acknowledgments: We thank Larry Purcell for providing us with seeds that were used in this study and Amanda Williams, Charlotte Snook, Joy Lydia Randall, Lydia Oswald, Matthew Savoca, Ricardo St. Aime, Harrison Gregory Fried, Zolian Sang Zoong Lwe, and Nicholas Accardo for their help in data collection. This publication is Technical Contribution No. 6672 of the Clemson University Experiment Station.

Conflicts of Interest: The authors declare no conflict of interest. The funders had no role in the design of the study; in the collection, analyses, or interpretation of data; in the writing of the manuscript, or in the decision to publish the results.

\section{References}

1. SoyStats 2018. A Reference Guide to Important Soybean Facts and Figures. American Soybean Association. Available online: http:/ / soystats.com/ (accessed on 01 February 2019).

2. Palmer, J.; Dunphy, J.E.; Reese, P. Managing Drought Stressed Soybeans in the Southeast; NC Cooperative Extension Service: Raleigh, NC, USA, 1996.

3. Specht, J.E.; Hume, D.J.; Kumudini, S.V. Soybean yield potential - a genetic and physiological perspective. Crop Sci. 1999, 39, 1560-1570. [CrossRef]

4. Purcell, L.C.; Specht, J.E. Physiological traits for ameliorating drought stress. In Soybean: Improvement, Production, and Uses, Agronomy Monograph 16, 3rd ed.; Boerma, H.R., Specht, J.E., Eds.; ASA/CSSA/SSSA: Madison, WI, USA, 2004; pp. 569-620.

5. Zipper, S.C.; Qiu, J.; Kucharik, C.J. Drought effects on US maize and soybean production: spatiotemporal patterns and historical changes. Environ. Res. Lett. 2016, 11, 094021. [CrossRef]

6. Sloane, R.J.; Patterson, R.P.; Carter, T.E., Jr. Field drought tolerance of a soybean plant introduction. Crop Sci. 1990, 30, 118-123. [CrossRef]

7. Carter, T.E., Jr.; De Souza, P.I.; Purcell, L.C. Recent advances in breeding for drought and aluminum resistance in soybean. In Proceedings of World Soybean Conference VI, Chicago, IL, USA, 4-7 August 1999; Kauffman, H., Ed.; Superior Print: Champaign, IL, USA, 1999; pp. 106-125.

8. Pathan, M.S.; Lee, J.D.; Shannon, J.G.; Nguyen, H.T. Recent advances in breeding for drought and salt stress tolerance in soybean. In Advances in Molecular Breeding toward Drought and Salt Tolerant Crops; Jenks, M.A., Hasegawa, P.M., Jain, S.M., Eds.; Springer: Dordrecht, The Netherlands, 2007; pp. 739-773.

9. Sinclair, T.R.; Purcell, L.C.; King, C.A.; Sneller, C.H.; Chen, P.; Vadez, V. Drought tolerance and yield increase of soybean resulting from improved N2 fixation. Field Crops Res. 2007, 101, 68-71. [CrossRef]

10. Purcell, L.C.; King, C.A.; Ball, R.A. Soybean cultivar differences in ureides and the relationship to drought tolerant nitrogen fixation and manganese nutrition. Crop Sci. 2000, 40, 1062-1070. [CrossRef]

11. Carter, T.E., Jr.; Todd, S.M.; Gillen, A.M. Registration of 'USDA-N8002' soybean cultivar with high yield and abiotic stress resistance traits. J. Plant Regist. 2016, 10, 238-245. [CrossRef] 
12. Sionit, N.; Kramer, P.J. Effect of water stress during different stages of growth of soybean. Agron. J. 1977, 69, 274-278. [CrossRef]

13. Senaratna, T.; McKersie, B.D. Dehydration injury in germinating soybean (Glycine max L. Merr.) seeds. Plant Physiol. 1983, 72, 620-624. [CrossRef] [PubMed]

14. Georgia Soybean Production Guide 2018. The Univ. of Georgia College of Agricultural and Environmental Sciences. Available online: http:/ / www.caes.uga.edu/content/dam/caes-website/extension-outreach/ commodities/grains/docs/soybean/2018-Soybean-Production-Guide.pdf (accessed on 1 February 2019).

15. Torrion, J.A.; Setiyono, T.D.; Cassman, K.G.; Ferguson, R.B.; Irmak, S.; Specht, J.E. Soybean root development relative to vegetative and reproductive phenology. Agron. J. 2012, 104, 1702-1709. [CrossRef]

16. Hufstetler, E.V.; Boerma, H.R.; Carter, T.E.; Earl, H.G. Genotypic variation for three physiological traits affecting drought tolerance in soybean. Crop Sci. 2007, 47, 25-35. [CrossRef]

17. King, C.A.; Purcell, L.C.; Brye, K.R. Differential wilting among soybean genotypes in response to water deficit. Crop Sci. 2009, 49, 290-298. [CrossRef]

18. Dhanapal, A.P.; Ray, J.D.; Singh, S.K.; Hoyos-Villegas, V.; Smith, J.R.; Purcell, L.C.; King, C.A.; Cregan, P.; Song, Q.; Fritschi, F. Genome-wide association study (GWAS) of carbon isotope ratio ( $\delta 13 \mathrm{C})$ in diverse soybean [Glycine max (L.) Merr.] genotypes. Theor. Appl. Genet. 2015, 128, 73-91. [CrossRef] [PubMed]

19. Dhanapal, A.P.; Ray, J.D.; Singh, S.K.; Hoyos-Villegas, V.; Smith, J.R.; Purcell, L.C.; King, C.A.; Fritschi, F.B. Genome-wide association analysis of diverse soybean genotypes reveals novel markers for nitrogen traits. Plant Genome 2015, 8. [CrossRef]

20. Kaler, A.S.; Ray, J.D.; Schapaugh, W.T.; King, C.A.; Purcell, L.C. Genome-wide association mapping of canopy wilting in diverse soybean genotypes. Theor. Appl. Genet. 2017, 130, 2203-2217. [CrossRef] [PubMed]

21. Chen, P.; Sneller, C.H.; Purcell, L.C.; Sinclair, T.R.; King, C.A.; Ishibashi, T. Registration of soybean germplasm lines R01-416F and R01-581F for improved yield and nitrogen fixation under drought stress. J. Plant Reg. 2007, 1, 166-167. [CrossRef]

22. Sadok, W.; Gilbert, M.E.; Raza, M.A.; Sinclair, T.R. Basis of slow-wilting phenotype in soybean PI 471938. Crop Sci. 2012, 52, 1261-1269. [CrossRef]

23. Lee, G.J.; Carter, T.E., Jr.; Boerma, H.R.; Shannon, J.G.; Hood, M.; Hawbaker, M. Identification of soybean yield QTL in irrigated and rain-fed environments. In Agronomy Abstracts; ASA, CSSA, and SSSA: Madison, WI, USA, 2002.

24. Uniform Soybean Tests Southern States 2017. USDA-Agricultural Research Service Crop Genetics Research Unit, Stoneville, MS. Available online: https://www.ars.usda.gov/ARSUserFiles/60661000/ UniformSoybeanTests/2017SoyBook\%20lockedREV.pdf (accessed on 1 February 2019).

25. Kolasinska, K.; Szyrmer, J.; Dul, S. Relationship between laboratory seed quality tests and field emergence of common bean seed. Crop Sci. 2000, 40, 470-475. [CrossRef]

26. International Rules for Seed Testing: Rules; International Seed Testing Association (ISTA): Zurich, Switzerland, 2004; p. 243.

27. Fehr, W.R.; Caviness, C.E. Stages of Soybean Development; Special Report 80; Iowa Agricultural and Home Economics Experiment Station Publications, Iowa State University: Ames, IA, USA, 1977.

28. McCarter, K.S. Analysis of covariance. In Applied Statistics in Agricultural, Biological, and Environmental Sciences; Glaz, B., Yeater, K.M., Eds.; ASA/CSSA/SSSA: Madison, WI, USA, 2018; pp. 235-277.

29. Association of Official Seed Analysts (AOSA). Rules for Testing Seeds; Association of Official Seed Analysts (AOSA): Wichita, KS, USA, 2017.

30. Taylor, H.M.; Burnett, E.; Booth, G.D. Taproot elongation rates of soybeans. Z. Acker Pflanzenbau Bd. 1978, 146, 33-39.

31. Manavalan, L.P.; Guttikonda, S.K.; Tran, L.P.; Nguyen, H.T. Physiological and molecular approaches to improve drought resistance in soybean. Plant Cell Physiol. 2009, 50, 1260-1276. [CrossRef] [PubMed]

32. Fried, H.G.; Narayanan, S.; Fallen, B. Characterization of a soybean (Glycine max L. Merr.) germplasm collection for root traits. PLoS ONE 2018, 13, e0200463. [CrossRef] [PubMed]

(C) 2019 by the authors. Licensee MDPI, Basel, Switzerland. This article is an open access article distributed under the terms and conditions of the Creative Commons Attribution (CC BY) license (http:/ / creativecommons.org/licenses/by/4.0/). 